\title{
全新世江汉平原地区长江南移年代 的沉积学依据
}

\author{
朱育新 王苏民 吴瑞金 \\ (中国科学院南京地理与湖泊研究所湖泊沉积与环境开放实验室, 南京 210008)
}

\section{关链词长江南移 年代 沉积依据 全新世 江汉平原}

江汉平原是长江和汉水的冲积湖积平原, 是古云梦泽 ${ }^{[1]}$ 所在地. 全新世以来长江和汉水 河道在此多次迁移, 由于由西北向东南新构造掀斜运动和科氏力的作用总体南移, 制江河曲现 代仍在继续发展 ${ }^{[2 \sim 4]}$. 对于长江河道的迁移, 历来的研究均以古地貌和史藉记载为主要依 据, 这就受到一定的局限. 本文对江汉平原第四纪沉积中心㑂城钻孔 (M1 孔) 岩芯进行粘土 矿物、稀土元素、陆源性常量元素、磁化率和频率磁化率等多环境指标分析, 研究沉积物物源的 明显改变来推论河道的迁移, 由 ${ }^{14} \mathrm{C}$ 测年得出长江南移的年代, 并探讨了南迁前后的环境剧变 与古云梦泽的演化.

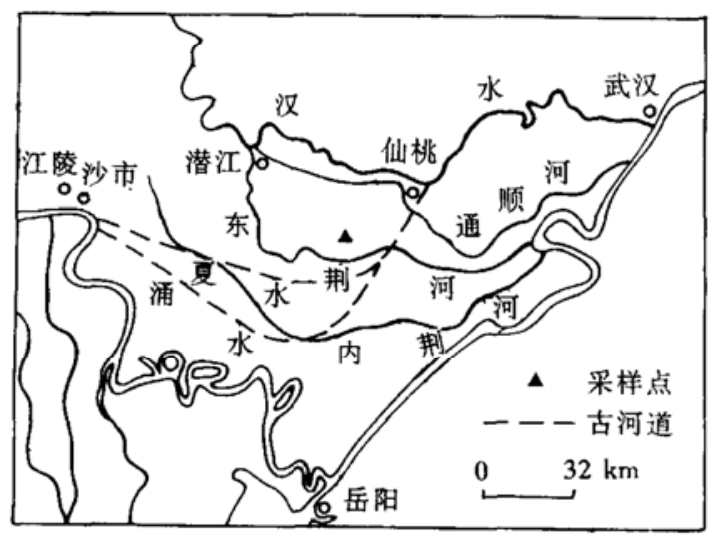

图 1 江汉平原水系变迁 ${ }^{[4]}$ 及 $\mathrm{M} 1$ 孔地理位置图

M1 孔位于湖北省仙桃市㑂城镇 (图 1), 孔深 $56.18 \mathrm{~m}$, 于 1992 年 10 月采样, 本文仅分析 $40.3 \mathrm{~m}$ 以上部分. M1 孔岩性以粉砂、泥质粉砂、 粉砂质泥和泥为主, 体现出冲积湖积平原的一般 特点. $40.3 \sim 12.9 \mathrm{~m}$ 以灰色粉砂、细砂、泥质粉 砂和粉砂质泥及其互层为主, 为河间洼地和不稳 定的浅湖环境; $12.9 \mathrm{~m}$ 以上泥质成分增加, 其中 12.9 10m 和6.7 $3.9 \mathrm{~m}$ 为灰色至深灰色泥, 反 映为稳定的开阔湖沉积.

\section{1 样品与分析方法}

数据见后面图 3.

${ }^{14} \mathrm{C}$ 年代由国家地震局地质研究所测定, 具体

粘土矿物成分定性分析由国产 Y3 型 X-射线衍射仪直接进行样品测定.

REE 含量测定按文献 [5]定量分离沉积物中的稀土元素, 由美国产 Jarrel-Ash 1100 型电 感耦合等离子体原子发射光谱仪 (ICP-AES) 测定各稀土元素含量, 并计算出总量.

陆源性元素 $\mathrm{Fe}, \mathrm{Al}, \mathrm{Ca}, \mathrm{Mg}$ 测定采用 $\mathrm{HF}-\mathrm{HClO}_{4}-\mathrm{HCl}$ 溶解沉积物样品由美国产 ILPLASMA-200 型 ICP-AES 测定各元素含量.

磁化率 $\left(\chi_{1 \mathrm{ff}}\right)$ 和频率磁化率 $\left(\chi_{\mathrm{fd}}\right)$ 测定按文献 $[6]$ 的方法进行.

\section{2 结果与讨论}

利用 X-衍射法对 8 个样品进行定性分析 (图 2), 结果发现, 样品 M30 (4.96 m)、M52 
$(6.34 \mathrm{~m}) 、 \mathrm{M} 170(12.28 \mathrm{~m})$ 含长石、石英、伊利 石、高岭石、绿泥石等普通粘土矿物, 而 M289 $(18.93 \mathrm{~m}) 、 \mathrm{M} 392(24.21 \mathrm{~m}) 、 \mathrm{M} 463(29.58 \mathrm{~m}) 、$ M545 (33.96 m) 和 M590(36.2 m) 中除含上述 粘土矿物外, 还含有白云石和方解石. 由于该 区成湖时为淡水湖泊, 这些白云石和方解石不 是自生的, 而是外源性的, 这就初步表明 M1 孔 的物源在 $12.28 \mathrm{~m}$ 和 $18.93 \mathrm{~m}$ 之间某处发生了 改变.

稀土元素、陆源性常量元素、磁化率和频率

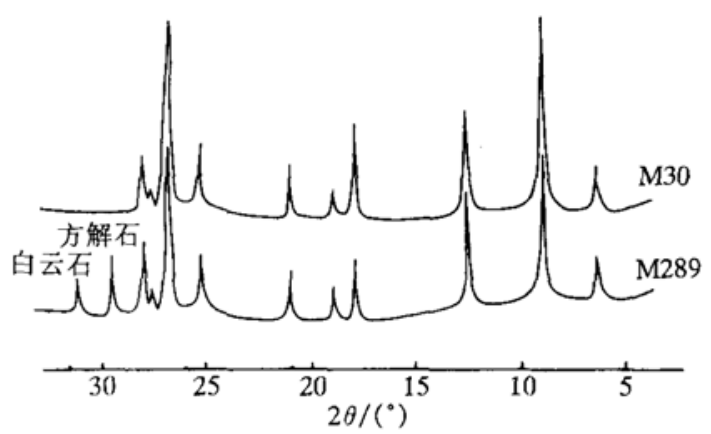

图 2 M1 孔样品 X 衍射定性分析结果 磁化率的测定结果见图 3. 从图 3 中可以看出, 所有指标均存在一个明显界线一 $-12.9 \mathrm{~m}$, 以 此为界可以将 $\mathrm{M} 1$ 孔沉积物分为上下两层, 上层和下层沉积物的各项指标均有明显的差别(表 1).

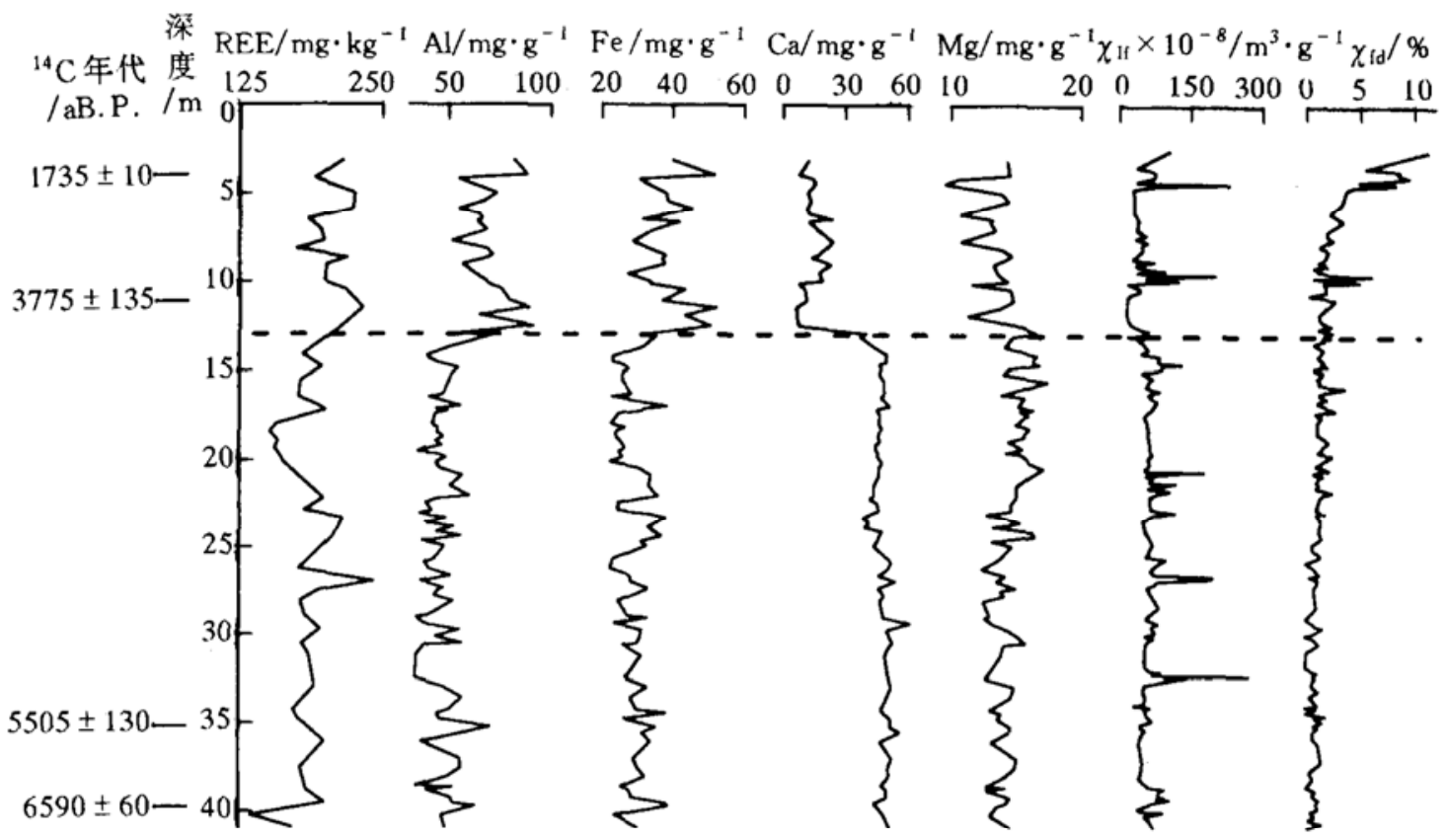

图 3 M1 孔稀土元素、常量元素、磁化率和频率磁化率垂直分布图

表 1 M1 孔上层和下层沉积物的各项指标测定结果

\begin{tabular}{cccccccc}
\hline & $\begin{array}{l}\mathrm{REE} \text { 总量 } \\
/ \mathrm{mg} \cdot \mathrm{kg}^{-1}\end{array}$ & $\mathrm{Fe} / \mathrm{mg} \cdot \mathrm{g}^{-1}$ & $\mathrm{Al} / \mathrm{mg} \cdot \mathrm{g}^{-1}$ & $\mathrm{Ca} / \mathrm{mg} \cdot \mathrm{g}^{-1}$ & $\mathrm{Mg} / \mathrm{mg} \cdot \mathrm{g}^{-1}$ & $\times 10^{-8} / \mathrm{m}^{3} \cdot \mathrm{kg}^{-1}$ & $\chi_{\mathrm{fd}} / \%$ \\
\hline 上层 & 207 & 38.2 & 68.9 & 15.3 & 13.3 & 57 & 3.15 \\
下层 & 184 & 29.6 & 47.2 & 48.0 & 14.7 & 75 & 1.26 \\
\hline
\end{tabular}

一般来说, 稀土元素最稳定, 不易受沉积环境的影响, 因此可作为区分物源的有效指标. 钻孔中上层和下层沉积物的稀土总量有所差别, 上层和下层沉积物的稀土元素分布模式也有 一定的差别(图 4). 陆源性常量元素的分布主要受母岩控制, 受气候与沉积环境的影响相对 较小. $\mathrm{Ca}$ 和 $\mathrm{Mg}$ 的含量增大与沉积物中含有白云石和方解石相对应. 磁化率主要取决于沉 
积物中磁性矿物的种类和含量, 这由物源决定, 但磁化率也受沉积环境的影响 ${ }^{[7,8]}$. 频率磁化 率揭示沉积物中磁性矿物的磁颗粒粗细, 尽管人类活动在一定程度上能导致频率磁化率增 $大^{[9]}$, 但主要仍受物源控制.

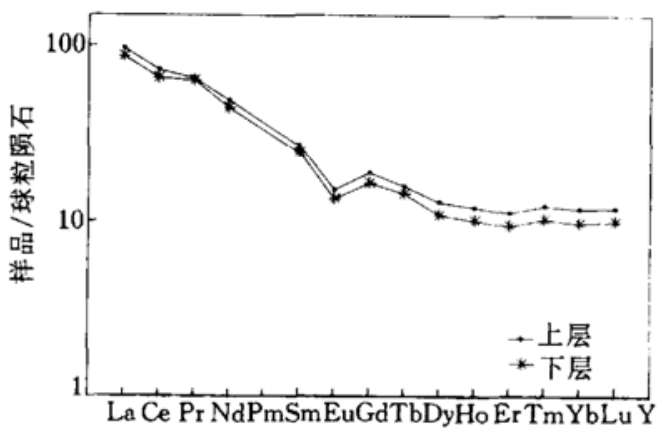

图 4 M1 孔上、下层样品的稀土元素分布模式

由以上分析结果, 可以认为 $\mathrm{M} 1$ 孔在 $12.9 \mathrm{~m}$ 前 后沉积物物源发生了改变. 据 ${ }^{14} \mathrm{C}$ 年代测定结果, $11.2 \mathrm{~m}$ 为 $(3775 \pm 135) \mathrm{aB} . P$. , $35.2 \mathrm{~m}$ 为 $(5505 \pm$ 130) aB. P. ; 按平均沉积速率推算, $12.9 \mathrm{~m}$ 处相当 于 $3.9 \mathrm{ka} \mathrm{B} . P$., 因此可以说 $3.9 \mathrm{ka} \mathrm{BP}$ 前后 M1 孔 物源有较大变化.

根据古地貌资料分析, 中全新世长江在沙市附 近主要有两条向东且经过河阳的分流河道, 也就是 先秦时期的夏水和涌水 (图 1). 这两条分流河道曾 经是㑂城钻孔沉积物的主要来源, 但当 $3.9 \mathrm{ka} \mathrm{B.P.}$ 前后长江主泓南移后, 夏水和涌水流量开始减少, 对㑂城地区的影响也变小, 相应地汉水影响 加大, 沉积物物源就此改变. 由于长江输沙量比汉水大, 这就造成 M1 孔上层沉积速率小, 下 层沉积速率大.

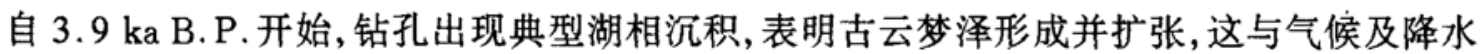
有关, 而作为江汉平原地区最大出水河道的长江向南迁移, 也是该区形成大范围湖泊的重要原 因.

致谢 夏威岗、賠文川、马燕、史复祥、吴锡浩、蒋复初、肖华国参加打钻采样, 张立仁进行 X-射 线衍射测定, 薛滨提供有益的建议, 张辉玉清绘图件, 在此一并表示感谢. 本工作为中国科学 院重点科研资助项目 (Z-011).

\section{参考 文献}

1 谭其猝. 云梦与云梦泽. 复旦学报(社会科学版), 历史地理专辑, 1980, (增刊) : 1 11

林承坤, 陈钦峦. 制江河曲的形成与演变. 南京大学学报 (自然科学版), 1965, 9(1): 97 122

周风琴. 云梦泽与荆江三角洲的历史变迁. 湖泊科学, 1994,6(1):22 31

中国科学院 (中国自然地理)编辑委员会. 中国自然地理 (历史自然地理)。北京: 科学出版社, 1982.88 93

郑春荣, 沈壬水. 直流等离子体光谱法测定土壤中的稀土元素. 光谱学与光谱分析, 1989,8(4): 32 35

6 吴瑞金. 湖泊沉积物的磁化率、频率磁化率及其古气候意义. 湖泊科学, 1993, 5(2): 128 135

7 Yu L Z, Oldfield F, Wu Y S, et al. Paleoenvironmental implications of magnetic measurements on sediment core from Kunming Basin, Southwest China. J Paleolimnol, 1990, (3): 95 111

8 王建, 刘泽纯, 姜文英, 等. 磁化率与粒度、矿物的关系及其古环境意义．地理学报, 1996, 51(2)：155～163

9 俞立中, 许 羽, 许世远, 等. 太湖沉积物的磁性特征及其环境意义. 湖泊科学, 1995, 7(2): 141 150 